\title{
Analysis on the Advantages and Disadvantages of Criminal Reconciliation Customs in Ganzi Tibetan Area
}

\author{
Shuguo Liu \\ Sichuan Minzu College, Ganzi, Sichuan, 626001
}

Keywords: customary law; Ganzi Tibetan Area; criminal reconciliation customs

\begin{abstract}
The criminal reconciliation custom in the Ganzi Tibetan Region is a national customary criminal law in nature. It plays a non-negligible role in the harmonious and stable society in the Ganzi Tibetan Region, and it is easier for the local people to accept disputes in favor of it, which is beneficial to the cost savings of the judiciary, and improve judicial efficiency, but there are also drawbacks that are difficult to overcome based on the nature of customary law. The construction of a criminal reconciliation system in Tibetan communities should fully consider the local tradition of criminal reconciliation.
\end{abstract}

\section{Introduction}

China is a unified country with many ethnic groups. The cultures of all ethnic groups have given birth to the Chinese civilization. The legal culture of all ethnic groups is an integral part of our legal culture. The traditional customs of criminal reconciliation is one of the main ways for people in Tibetan areas to resolve criminal disputes. It plays a non-negligible role in the harmonious and stable society in Tibetan areas and has certain drawbacks. This paper analyzes the advantages and disadvantages of the criminal reconciliation customs in Ganzi and Tibetan areas, and discusses the problems of constructing the criminal reconciliation system in Tibetan areas.

\section{The Main Features of Criminal Reconciliation Customs in Ganzi Tibetan Region}

The custom of criminal reconciliation in Ganzi Tibetan Autonomous Region is a typical national criminal customary law. The customary law has a strong religious, ethnic, and native nature, and often the laws combine, and civil penalties are not separated. All ethnic minorities in China have their own religious beliefs. The national criminal customary law is the accumulation of various nationalities based on their unique political, economic, and cultural characteristics in the course of their own historical development. It is the foundation of a nation's native criminal law culture. It is complementary to the application of national criminal law in ethnic minority areas. A nation's criminal law culture will be deeply impressed by the culture of native criminal law, no matter how powerful the external force is. National criminal customary law as a relatively stable and active important carrier of the original criminal law is a kind of "quasi-legal norms". As a nation where all people believe in Buddhism, religion has always played an important role in customary law. It has deep-rooted influence on the Tibetan customary law and it has penetrated deeply. The lives of the local people were strongly influenced and influenced by their own customary culture. They are convinced of their customary laws and are committed to obeying them. In addition, the ethnic minorities of China are mostly located in remote areas, with sparsely populated land and inconvenient transportation. In addition, the infiltration of judicial resources of the dynasties (including contemporary) is insufficient, so that the customary laws of all ethnic groups generally attach importance to the use of "mediation" to resolve disputes. One of the most common features of customary law is of course the customary law of the Ganzi Tibetan region. In the long-term practice of life, people have formed a series of effective dispute resolution mechanisms applicable to the region.

The criminal reconciliation in the Ganzi Tibetan Autonomous Region is a kind of civil mediation. In addition to the parties to the dispute, the participating parties also need mediation among highly 
respected individuals. The composition of the mediator in the middle has a diversity. Mostly: (1) religious figures. That is, the monks, monks and monks in the temples, such as the Living Buddha, Khenpo, and the Warriors. (2) There are prestige people. Such as family mediation to resolve, it is in this family has a greater influence on the elders. (3) The descendants of some of the chiefs of the Tusi. (4) The relatives of the parties are the elders. (5) Some retired cadres and workers (local). (6) Personnel in individual grassroots organizations. The identities of private mediators are also more complicated, some are single identities, but most have dual or even multiple identities. [1]

The application scope of criminal reconciliation customs in the Ganzi Tibetan Autonomous Region far exceeds the provisions of China's Criminal Law and Criminal Procedure Law. According to the provisions of the Criminal Procedure Law, criminal reconciliation is only applicable to cases of personal infringement where the penalty may be less than three years imprisonment, intentional crimes in property infringement, and criminal cases where the penalty other than malfeasance crimes may be less than seven years in prison. The customs of criminal reconciliation in Tibetan areas cover almost all common crimes committed by the people. They include minor injuries, thefts, and other crimes, as well as murders, robbery, rapes, and heavy injuries.

\section{Advantages and Disadvantages of Criminal Reconciliation Customs in Ganzi Tibetan Region}

First, the criminal reconciliation customs in Ganzi and Tibetan areas are consistent with the core values of the current criminal reconciliation system. "Crime and victimization are two sides of a coin." One-sided attention to offenders means excessive oblivion to the victim. Recovery will shift the focus of attention from traditional criminals to more vulnerable victims. The compensation for victims' material losses, the solace of emotional harm, and the urgent need to return to society are pursued as the central goal in reconciliation. [2] The establishment of a criminal reconciliation system marks the transition of criminal justice concepts from punitive justice to restorative and compensatory justice. Taking the custom of "paid-for-price" and "money-reducing price" that are popular in Tibetan areas to resolve disputes concerning killing and injury, the parties' compensation through private mediation is often higher than that obtained through direct judicial channels. As the saying goes, "One party loses one, and one loses money." The amount of the compensation agreement reached by other civil mediation of criminal disputes is often higher than the amount of compensation obtained through the judicial process, and many times it is carried out by the relatives of the suspect or even the family on behalf of the suspect and the performance is rapid. The victim has achieved self through mediation. Demand for justice can receive a greater amount of economic compensation. Therefore, criminal reconciliation customs are generally accepted by the local farmers and herdsmen.

Second, criminal reconciliation customs are conducive to improving judicial efficiency and saving judicial costs. One of the important values of the criminal reconciliation system is to increase judicial efficiency and save judicial costs. This is particularly prominent in the Ganzi Tibetan region. The purpose of the Criminal Procedure Law is to better protect the legal rights of the parties. In the Ganzi Tibetan region, some procedural provisions of the Criminal Procedure Law are not fully functional due to restrictions on transportation, communications, and the environment. If the procedural provisions of the Criminal Procedure Law are strictly followed, from the investigation to the conclusion of the trial, it will be necessary. Long time. In this process, victims or their families may take retaliatory actions for their inability to receive timely compensation, leading to more serious criminal cases. Criminal reconciliation customs may enable some cases to bypass prosecution and trial in handling. Procedures to more effectively address the attribution of responsibilities. At the same time, criminal reconciliation customs have a profound social foundation in Tibetan areas. Reconciliation is based on incomplete old laws and traditional customs, which are flexible and easily accepted by the masses. The grass-roots judicial work in the Ganzi Tibetan area has its insurmountable weaknesses, and it is often time-consuming and laborious for the peasants and herdsmen to take normal channels to resolve disputes, especially damages and compensation after the killings, so the parties are generally unwilling to go far to report crimes. It is 
the choice of private "private". Not only saves costs, but also helps resolve conflicts in a timely manner. [3]

First of all, there is a certain conflict between the customs of criminal reconciliation in the Ganzi Tibetan area and the statutory law of national unity. There is an inverse relationship between statutory law and customary law. When customary law is used universally, statutory law is useless. The widespread application of criminal reconciliation customs in the Ganzi Tibetan Autonomous Region will inevitably result in the exclusion of modern criminal justice based on the National Criminal Law. As mentioned above, the criminal reconciliation stipulated in the Statute of the People's Republic of China is only applicable to personal infringement where the penalty may be less than three years imprisonment, intentional crimes in property infringement and penalties other than dereliction of duty may be guilty of negligent crimes with a term of imprisonment of up to seven years. case. The criminal reconciliation in the Ganzi Tibetan region covers almost all the common crimes in the civil society. The scope of application clearly exceeds the provisions of the statute law. In the absence of relevant laws, there are quite a few legal settlements for criminal settlements. In addition, from the perspective of criminal reconciliation, some contents clearly violate national laws. If the contractor's home ownership is not allowed and he is not allowed to live in the original place of residence, he will be responsible for the family members and even family responsibilities on the compensation obligation. [4]

Second, the arbitrariness of customary law and the diversity of subjects involved in criminal reconciliation practices have led to uncertainty in their application. The criminal reconciliation customs pay attention to economic compensation, and there is no uniform compensation standard in the customary law. The standard of compensation is often determined by the social status of the party. In addition, although some mediators in central China have high prestige, they are inevitably biased in mediation because of their lack of grasp of state laws and policies and their understanding of the spirit of modern rule of law. In practice, there is such a situation: From the perspective of the victim, if the family or the family has a large power, the benefits that are often obtained will be large, and the benefits will be small. Judging from the injuring party, the amount of compensation is huge, ranging from tens of thousands to hundreds of thousands and millions. There have even been cases in which some families have poured out all their compensation to the victims, causing the injurers to have nothing to do with them or even to leave their homes, adding new destabilizing factors to social management. The existence of these conditions hindered the process of criminal rule of law in the Ganzi Tibetan region.

\section{Conclusion}

In social governance, "apprentice law is not enough to be self-reliant", and in the construction of the legal system, "orphan law is difficult to self-respect". There is no criminal law suitable for Tibetan areas as a guide. A separate criminal procedural law is far from satisfying the judicial work needs of the Ganzi Tibetan area. The criminal law includes the criminal substantive law and the criminal procedural law, and China has already formulated the criminal law and the criminal procedure law that are uniformly applied throughout the country. Although the Constitution, the Law of Legislation, and the laws of various branches have stipulated that ethnic autonomous areas may formulate autonomous regulations and separate regulations based on ethnic characteristics, so far, the provisions for criminal modification in various ethnic autonomous areas still cover the issue. This situation makes the criminal reconciliation customs in the Ganzi Tibetan Area in an embarrassing situation. In essence, criminal reconciliation customs play a certain role in stabilizing and stabilizing the society, but in form, it has a customary law. The nature of which is outside the national jurisdiction. The reason is that one aspect of the principle of a legally prescribed punishment for a specified crime is the exclusion of the application of customary law. This situation has resulted in the fact that in some ethnic areas (including the Ganzi and Tibetan areas), judicial practice often occurs not with "according to facts and with the law as the yardstick," but rather with the fact that the law is legal, and facts and laws do not seem to Coherent dilemma.

The construction of the rule of law is a systematic work. Legislation, law enforcement, judicature, 
and compliance with the law are a coordinated and unified process. For ethnic areas, "the law that can be effectively implemented is precisely those that are consistent or similar to the prevailing customary practices." "A law that can only be carried out by state coercive power, even if it is justified in theory, will certainly fail." [[5] "This law is neither engraved on marble nor on bronze. It is engraved in the hearts of citizens; it forms the real constitution of the country; it gains new strength every day; when other laws age or die, it can resurrect those laws or replace those laws, it can maintain a The creation spirit of the nation and the unconscious use of the power of custom to replace the power of authority.6 The traditional practice of criminal reconciliation in Tibetan areas provides a practical soil for the establishment of a broader scope of criminal reconciliation in the Ganzi Tibetan area. It is generally believed that in the traditional cultures of all countries in the world, there are various factors of modernity, implicitly or implicitly. What the world more generally agrees is that in the course of the modernization of any country, it is necessary to make reasonable use of tradition. Or creative transformation of tradition to find a unique path for its own development.7 Therefore, the construction of a criminal reconciliation system in Tibetan areas should be completed. Consider the traditional customs of criminal reconciliation.

\section{References}

[1] [3] [4] See also: "The People's Court of xxx Research Report on the Participation of Gaoming Dade in Folk Participation in the Ganzi Tibetan Region Temples", 2012.

[2] Du Yu: The Theory of Criminal Reconciliation and Traditional Criminal Responsibility, Law Research, No. 1, 2009, p. 89. [5] Suli: "Rule of Law and Its Local Resources", China University of Political Science and Law Press, 2004 edition, p. 10.

[6] [Method] Rousseau, He Zhaowu Translation: "Social Contract Theory", Commercial Press, 2007 edition, p. 70.

[7] Zhang Haibin, "Village Autonomy and Rule of Law in a Transitional Society,” 2010 East China University of Politics and Doctoral Dissertation, p. 21. 